\title{
EL HÉROE LITERATURA Y PSICOLOGÍA ANALÍTICA
}

José M. Rodríguez Zamora

\begin{abstract}
RESUMEN
El artículo presenta una aproximación al mito del héroe, fundamental en el discurso literario, desde la psicología analítica propuesta por Carl Jung. Se estudia su origen, su desarrollo y sus consecuencias literarias como arquetipo funcional de la narrativa.

Palabras clave:mito, héroe, psicología analítica, discurso narrativo, arquetipo.
\end{abstract}

\section{ABSTRACT}

This article presents an approximation to the myth of the hero, fundamental within the literary discourse, from the analytical psychology proposed by Carl Jung. It discusses its origin, its development and its literary consequences as a functional archetype of the narrative.

Key words: myth, hero, analytical psychology, narrative discourse, archetype

La principal hazaña del héroe es vencer al monstruo de la oscuridad: el triunfo largamente esperado de la conciencia sobre el inconsciente.

C. G. Jung, Acerca de la psicología del arquetipo del niño. (1940)

\section{EI héroe escucha la llamada}

Es fácil seguir el camino. Más fácil perder el rumbo. El mito del héroe es esencialmente un viaje que se emprende por una llamada imperativa. Es respuesta y odisea. Inevitablemente, cada ser humano se embarca en el viaje y navega, con mayor o menor pericia, por el mar de la existencia subjetiva, que es a la vez universal. De esta manera, el hombre y la mujer requieren

Ph. D. José M. Rodríguez Zamora. Máster en Lingüística. Máster en Psicología Clínica. Catedrático de la Universidad de Costa Rica.

Correo electrónico: jomiroz@gmail.com

Recepción: 07- 12- 2009

Aceptación: 11- 01- 2010 
enfrentarse con aquellos personajes en el teatro de la inconsciencia: arquetipos, anima y animus, sombra y otros monstruos terribles, hadas benéficas y traviesos duendes que emergen del fondo de la historia primigenia. La noche de los tiempos, esa elusiva metáfora, no hace sino referencia a nuestra noche y a nuestro tiempo inconscientes desde donde brota el mito largamente compartido. Mitos, sueños y misterios, como si de un texto de Eliade se tratara son, a la vez, el timón, la vela y la brújula, en este peligroso e inevitable viaje.

El texto literario es un bosque privilegiado donde crecen continuamente los mitos ancestrales. Surge del suelo nutricio del inconsciente colectivo, pero se afirma con originalidad propia en cada época, de acuerdo con la singularidad del o la escritora que lo revive desde su alma. Singularidad y colectividad, esta es la paradoja de la fantasía y de la realidad presente en los sueños, los cuentos, los mitos, las alucinaciones y en el espacio recurrente de la literatura.

Con respecto a la expedición del héroe, esta es vivida como ruptura con el dragón; en este caso, símbolo de la atadura con el hogar primigenio y protector; es decir, el ánima atada a la madre. Debe cortar el cordón umbilical para salir del seno materno, alma mater o tierra nutricia, y autoafirmarse como individuo. Para la psicología femenina, el viaje del héroe reviste una forma un tanto diferente. En este caso, se vive a través de las hazañas del ánimo (animus) o de la proyección emocional. Es distinto lo que ocurre con el mito de la diosa, según el cual la mujer vive su realización psíquica personal a través de su propia alma y el hombre vive a través de la suya en forma derivada o con la identificación proyectiva con una compañera.

El ser humano existe en un mundo de signos, símbolos, mitos y metáforas. Sin ellos, la especie se hubiera extinguido hace milenios, porque parece incuestionable que el mito desempeña un papel esencial en la vida cotidiana y en el intercambio social; está en los fundamentos de la cultura y en la forma cómo contemplamos el mundo. Desde el mito se define nuestra acción o inacción, así como nuestro lugar en el universo. Aparece siempre mezclado con las creencias religiosas, culturales y políticas e incluso, girando alrededor del propio pensamiento científico. La vida humana, su desarrollo, su evolución personal o colectiva, ha estado marcada por el relato mítico ${ }^{1}$; pues, éste lo llama más allá de la historia y es al mismo tiempo instrumento de sobrevivencia ancestral. El mito es nuestro mundo.

El mito no implica, en modo alguno, la referencia exclusiva a las sociedades arcaicas o a fábulas sin verificación empírica, entendidas como narraciones irracionales o anti racionales. ${ }^{2}$ Las investigaciones científicas en la segunda mitad del siglo XX demostraron concluyentemente que no estamos lejos del mito. Somos parte del mito, o mejor dicho, el mito es parte esencial de todo hombre y de toda mujer. A diferencia de épocas pasadas, en las que se consideró al mito como una etapa anterior a la razón, como una pre-racionalidad, los estudios contemporáneos destacan su valor como factor cognoscitivo y esencialmente vital. Se considera al mito como una forma válida e indispensable para decir algo que es imposible comunicar de otra forma sino a través de la alusión simbólica. Afortunadamente, ese tiempo ya pasó. Hoy ya no se considera al mito como una representación arcaica e imperfecta de la razón, sino como un complemento necesario de los procesos cognitivos. Aunque no sea visible su significado, ello no implica que sea contradictorio con lo visible. El mito es conocimiento, no hay duda. ¿Será el conocimiento un mito?

Por otra parte, el mito, el símbolo y la religión se presentan como elementos unidos y omnipresentes en la cultura. ¿Quién podría establecer una clara línea divisoria entre ellos? ${ }^{3}$ Hasta el momento, y como lo demuestran la antropología y la historia, toda cultura y toda civilización conocidas, incluidas las actuales, giran alrededor de la religión, del mito y de 
los símbolos. Debe aclararse que no es la significación convencional del signo compartido funcionalmente; son símbolos que hablan con un significado al alma, cual las obras del bildungsroman, género literario que recoge la inquieta propensión formativa hacia el sí mismo, donde la tierra es escenario de transformación y de reencuentro del héroe de las mil caras (Campbell 1999). Historias como en Enrique de Ofterdingen de Novalis, el héroe busca su flor-azul (Blaue Blume), Santo Grial del sí mismo. Presente eterno reconstruido en las obras de Thomas Mann, Joyce, Hesse, Goethe, Tolstoi, Dostoievsky, Proust, V. Woolf, Salinger, I. Allende, Carlos Fuentes e incluso en Cien años de soledad de García Márquez, para no mencionar sino algunos nombres paradigmáticos.

También, el mito del héroe tiene su propia sombra. Es la víctima. El arquetipo de la víctima no es sino el resultado del héroe fracasado, o aún, del sujeto herido o sacrificado por el héroe en el terreno de la cruel derrota. También es sombra el culto al héroe, porque quien ofrece el culto no es otro que la víctima sumisa a los pies del héroe. El héroe, engreído y ambicioso, traiciona los grandes ideales y se convierte él mismo en víctima de la infatuación.

Para responder a tales cuestiones, este trabajo se enfocará en el estudio de la relación que existe entre la psicología analítica desarrollada por Jung y el mito del héroe. ${ }^{4} \mathrm{Se}$ comenzará por hacer una breve ubicación contextual de la psicoterapia analítica. Enseguida, y derivada de lo anterior, se hace una precisión sobre los arquetipos, más propiamente llamados invariantes cognitivos, y los tipos psicológicos. Las dos últimas partes tratarán con más detalle el tema propuesto, a saber, el camino del héroe y la individuación: sombra y selbst. Concluye esta investigación con algunas observaciones finales y las referencias bibliográficas correspondientes.

\section{La entrada en el laberinto}

La relación que existe entre la literatura y la psicología no siempre ha sido fluida ni armónica; más bien, ha suscitado frecuentes problemas. Obviamente, ello no se debe tanto al pretendido afán imperialista de la psicología, ni a la inveterada desconfianza de los literatos, sino a la complejidad intrínseca del propio discurso literario y a su carácter elusivo. Los esfuerzos de Freud por desentrañar las motivaciones inconscientes del escritor -y aún del lector-, no parece que ahora sean aceptables sin que medie una hermenéutica que reconstruya los criterios sobre los cuales se funda el análisis. Tampoco parecieran adecuados sin más los intentos de Lacan. La psicología y el psicoanálisis pueden esclarecer aspectos esenciales del objeto literario, pero no son suficientes. En este, como en cualquier otro caso, el reduccionismo y el fundamentalismo metodológico y epistemológico podrían negar la aproximación constitutiva del objeto literario ocasionando una clausura de la pluralidad significativa. El riesgo ha sido el de convertir los textos literarios en protocolos clínicos (García Berrío 1994) desplazando o anulando la poética del discurso ficcional en sentido estricto.

Aun así, el método psicológico aplicado a la literatura no es un esfuerzo vano, sino todo lo contrario, es un factor enriquecedor e iluminado; pues, es sabido que la obra literaria es abierta y susceptible de diversas aproximaciones interpretativas. Conviene, por lo tanto, tomar en cuenta estas precauciones y recordar que este objeto literario se construye con estructuras imaginarias desde las cuales surgen su poeticidad (García Berrio 1994: 430). Desde la óptica de la psicología analítica, los arquetipos constituyen la articulación subyacente de la expresividad literaria. En este caso, la teoría de los arquetipos propuesta por Jung supone 
la idea de macroestructuras que operan en la construcción del sentido poético, otorgándole a la ficcionalidad literaria no sólo el valor de la representación de lo existente, sino la función de articular un enlace entre la representación y la realidad. Fantasía, concepto, realidad y representación se articulan en la operatividad de los arquetipos; abre el espacio de la significación tal como lo había propuesto Derrida (Derrida 1989).

Una especie de semántica del arquetipo contribuye a romper el nominalismo epistemológico del análisis del discurso literario. De esta forma, el símbolo adquiere una dimensión cuasi ontológica con una actividad propia que establece una tensión dinámica entre la particularidad original y la representación colectiva. El texto revela su significado sin que por ello se encierre en una instancia monolítica; más bien, se abre a diversos estratos posibles de significación.

Desde las consideraciones anteriores, se puede proceder a revisar el arquetipo del héroe. ¿Quién o qué es el héroe? La respuesta siempre es elusiva. Para el psicólogo Carl Jung, el héroe simboliza el sí mismo consciente, aunque no en su totalidad. Es la suma total de todos los arquetipos. Es tanto el niño, como el padre y también el viejo sabio: "En este sentido el héroe es su propio padre y su propio procreador" (Jung 1984). El héroe deberá enfrentarse al demonio de la libido, las fuerzas instintivas. También a su propia sombra. Por este motivo, es un viajero que después de atravesar el desierto y el mar del inconsciente regresa a su hogar para encontrar la armonía de los contrarios, el sagrado matrimonio; es decir, la individuación integrada. Si bien el mito del héroe nace junto o desde la cultura de la incipiente ciudad, de la agricultura, la especialización laboral y la escritura en las antiguas civilizaciones de Mesopotamia y Babilonia, ${ }^{5}$ en realidad, cada persona de algún modo es o debería ser un héroe. Este arquetipo marca de forma notable el discurso literario desde las primeras narraciones épicas como Gilgamesh, también la narración de José y sus hermanos del Antiguo Testamento y el periplo de la Odisea, hasta las elaboradas novelas de nuestros días. De acuerdo con Jung,

\footnotetext{
El héroe es el tipo masculino ideal: al abandonar a la madre, origen de la vida, siente un deseo inconsciente que lo impulsa a encontrarla de nuevo, a volver a su útero. Cada obstáculo que surge en su camino y dificulta su ascenso, tiene las características sombrías de la Madre Terrible quien corroe su fortaleza con el veneno de la duda secreta y el anhelo retrospectivo. (Jung, citado en Sharp 1997:90)
}

Las creencias, es decir, estructuras de pensamiento que orientan la vida, tienen una función explicativa que desborda lo racional; suelen actuar como mitos, por lo que no siempre es fácil distinguirlas de ellos. A diferencia de los pensamientos, los mitos poseen un fuerte contenido imaginario que sirve como marco estructurador de los sentimientos y de las emociones, en consecuencia, inciden de forma directa en la conducta. Este hecho suscita varias cuestiones de singular importancia: ¿Cuál es el mito que se oculta detrás de cada creencia? ¿Cuál es el mito de cada persona? ¿Cuál mito da impulso o detiene una sociedad y una cultura? ¿Cuál fue el viaje heroico de Jung?

\section{Jung y el origen del arquetipo}

Es conveniente ubicar esta reflexión recordando varios datos sobre la vida del psicólogo suizo y del contexto dentro del cual surge la psicología analítica. De esta forma, se comprenderán mejor los conceptos fundamentales.

El fundador de la psicología analítica, Carl Gustav Jung, nace en Kesswil el 26 de julio de 1875, en medio de un entorno rural en el cantón de Turgovia, Suiza. Hijo de un 
pastor piadoso, pero irritable, quien a vez descendía de una religiosa familia de pastores; su madre era extravertida y comunicativa. En otras palabras, Jung viene al mundo en el seno de una familia desavenida. Esta ambivalencia marcará profundamente su personalidad. $\mathrm{Su}$ infancia estará sellada por la soledad y la reflexión. Su mundo de niño fueron los sueños, los verdes bosques, las montañas nevadas y los azules lagos de la naturaleza suiza. Ya desde joven Jung es un gran lector. Lee profusamente filosofía, teología, historia, literatura y ciencias naturales. Se decide por la medicina y, dentro de esta, por la psiquiatría. Sus estudios universitarios los realiza en Suiza, Alemania y Francia. Ya graduado, entra a trabajar como médico en el famoso Hospital para Enfermos Mentales de Burghölzli, cerca de la ciudad de Zurich. Poco después, se casa con una mujer notable, Emma Rauschenbach, con la cual tiene cinco hijos. También ella luego se forma como psicoterapeuta y llega a dar clase en el Instituto junguiano de Zurich.

El joven médico desde 1900 a 1907 continuó su trabajo en la clínica del reconocido psiquiatra Eugen Bleuler. Fue allí donde realizó estudios sobre la asociación de palabras y escribió un manual sobre la esquizofrenia. Gran viajero, quiso ver por sí mismo los diferentes pueblos y culturas. Conferencista, prolífico escritor, Jung crea alrededor de sí un círculo de intelectuales interesados en el estudio de las religiones, los mitos y la psicología; ${ }^{6}$ entre los asiduos visitantes están Mircea Eliade, Karl Kerényi, Erich Neumann y otros. Hoy aparece como un gigante que desbroza un camino hacia un mundo extrañamente conocido y oculto a la vez. Después de una larga vida, Jung muere en el año 1961.

Sobre su desarrollo intelectual, vale recordar lo siguiente. Su tesis de doctorado de 1902 tuvo como tema de estudio Sobre la psicología y patología de los llamados fenómenos ocultos. En ella, desarrolla una idea que será fundamental para su psicología posterior, a saber: en todo individuo hay una predisposición natural hacia una integración de la totalidad de la psique; dinámica de la psique que se irá desplegando a través de la vida de cada persona.

De esta primera época, viene también la importante construcción teórica del complejo y su relación con el inconsciente; por complejo se refiere a varios grupos o conjunto de ideas de importancia afectiva en la región inconsciente de la psique. También, sus trabajos sobre la neurosis y la psicosis, así como el uso terapéutico y el posterior abandono de la hipnosis en la psicoterapia. Son importantes las investigaciones empíricas que lo llevan a crear el famoso Test de Asociación que aún se utiliza como diagnóstico de la personalidad y en la orientación profesional. Además, hizo aportes en el campo de la psicología forense y la psiquiatría. Particular importancia revisten sus investigaciones científico-experimentales de naturaleza psicofísica sobre el fenómeno galvánico y pneumográfico.

Sin embargo, desde sus primeros trabajos, se nota cierta inconformidad con la teoría y los tratamientos psiquiátricos usuales de la época; actitud crítica que se manifiesta en su ensayo de 1907 Sobre la psicología de la dementia praecox. Durante varios años, Jung recogió una serie de material sobre la mitología, las creencias y las religiones que van a dar lugar a su famoso libro Transformación y símbolos de la libido de 1912 (en 1952 lo convierte en Símbolos de transformación), en el cual el concepto de inconsciente adquiere un significado notablemente amplio, en particular al extenderlo al ámbito de la cultura. Es interesante notar que en la obra de Jung se encuentra una ambivalencia, por un lado, la búsqueda del rigor científico y racional; por otro, la apertura a la dimensión mítico-espiritual.

Sus biógrafos coinciden en que la segunda etapa de su vida se inicia en 1907, a raíz de un importante encuentro con Freud; aunque ya desde antes habían tenido una relación epistolar 
e intercambio de escritos. Del psicólogo vienés acepta el método psicoanalítico y varias de las conclusiones, pero con reservas. Aunque Jung admira a Freud, sigue desarrollando su propia psicología. No podía admitir muchas de las doctrinas esenciales de Freud, tales como las del cumplimiento del deseo, la interpretación de los sueños y la de la sexualidad infantil. ${ }^{7}$ Durante siete años, Jung formará parte del movimiento psicoanalítico. Sin embargo, su enfoque radicalmente distinto se basaba en una Weltanschauung que difería de la Freud. Ciertamente, Jung estaba de acuerdo con Freud en la importancia del inconsciente, pero no en la concepción del mismo. En general, se ha señalado que las posiciones de Freud seguían basadas en las teorías del conocimiento y de la física mecanicista del S. XIX, de las cuales dedujo sus conceptos básicos del instinto, la libido y las pulsiones; mientras que las de Jung estaban vinculadas con las del desarrollo científico del S. XX que rompían con el rígido positivismo y materialismo reinante. Su amistad con el físico y Premio Nobel Wolfgang Pauli lo lleva a estudiar las obras coetáneas de la ciencia. En efecto, es importante no olvidar que Jung se inscribe en la tradición del pensamiento de la cual brotan la nueva física relativista y cuántica, la genética evolucionista y la astronomía cosmológica.

La ruptura con Freud se produce a raíz de una conferencia que Jung pronunció en el año 1912 en la Universidad de Fordham (Nueva York) y de la publicación de su obra ya mencionada Transformación y símbolos de la libido. Es importante destacar que este libro está marcado por la idea de que existe un paralelismo esencial entre los sueños y las fantasías individuales y el significado de los símbolos y mitos de la cultura. En otras palabras, que tanto los sueños y las fantasías del sujeto brotan de la misma fuente que las fantasías, mitos y símbolos de la sociedad. El estudio de paralelos mitológicos permite afirmar un origen común. Esta línea de reflexión, que se mostró fructífera, será uno de los hilos conductores de su psicología posterior, lo cual dio lugar al famoso concepto de inconsciente colectivo y posteriormente al de arquetipo. La psicología de Jung se construye sobre diversas polaridades u oposiciones, tales como lo individual y lo colectivo, racional e irracional, pasado y futuro, masculino y femenino, vigilia y sueño, introvertido y extravertido, entre otros. Su psicología busca la plena integración; considera al inconsciente como el origen del crecimiento personal y colectivo.

Como se dijo anteriormente, en diferentes oportunidades viajó por diversas regiones de la tierra, en particular, conociendo culturas indígenas y nativas:

\footnotetext{
Trataba de descubrir las analogías entre los contenidos de la psique inconsciente en el hombre occidental moderno y ciertas manifestaciones de la psique en los pueblos primitivos; así como sus mitos y cultos. También estudió las culturas asiáticas, pues siempre tuvieron especial importancia para él los símbolos religiosos y la fenomenología del budismo y del hinduismo y las enseñanzas de Lao Tse, Confucio y el budismo Zen. (Jacobi 1973:368)
}

En resumen, sus estudios lo condujeron a la mitología griega y a otras mitologías occidentales y orientales, al misticismo cristiano y la patrística, así como la gnosis, la cábala, y, sobre todo, la alquimia, derivando en sus últimos tiempos, hacia la física moderna y la parapsicología. ${ }^{8}$

Como es conocido, los intereses de Jung sobrepasaron los límites convencionales de la psiquiatría y de la psicología. Sus obras, que abarcan más de veinticinco tomos en la versión alemana (incluyendo la correspondencia), no son de lectura fácil. Ciertamente, es de irregular calidad, aunque siempre sugerente. Jung abrió un nuevo camino y su trabajo tiene las características de una obra pionera. 
En todas partes, buscó paralelos e intuiciones iluminadoras que proporcionaran una comprensión más profunda de los productos creadores del alma humana y sus eternamente reiteradas formas básicas y expresiones; aunque sobre todo fue en el simbolismo de la alquimia y la filosofía hermética donde halló asombrosas correspondencias con el proceso de desarrollo del ser humano. Después estaban los problemas importantes de los hechos corrientes, a los que trata con extraña clarividencia, dándole así nuevo significado al caos de nuestro mundo (Jacobi 1973:369).

\section{El viaje a través del desierto de los tipos psicológicos y el mar de la conciencia, el inconsciente y los arquetipos}

No es nada fácil salir del laberinto. Menos en la noche. Falsas entradas y salidas lo circundan. Pero el centro es único. Es en la propia cara desconocida donde se marcan los oscuros senderos del laberinto. Cuando se proyecta hacia el exterior, se convierte el entorno en un laberinto real. La primera tarea es, por supuesto, la de reconocernos en lo desconocido. Comenzamos entonces a florecer como un nuevo nacimiento. Es realizar casi lo imposible: aceptar que lo malo en los otros no es sino lo malo de uno mismo. Eliminar las proyecciones hechas hacia los otros, las cuales son nuestra propia sombra. Al hacerlo, perderán su efecto destructor. Es Gilgamesh reivindicado, el alma que recobra el proustiano tiempo de la infancia, o Pinocho convertido, ahora sí, en auténtico niño. Pero, ¿dónde se origina este cambio? ¿cuál es su fuente? En otras palabras, ¿cómo está formada la psique?

De acuerdo con Jung, la psique está conformada por tres componentes, a saber, la conciencia, el inconsciente personal y el inconsciente colectivo, los cuales interactúan continuamente. Esta interacción, aunque semejante, varía según los individuos. En efecto, de acuerdo con esta teoría existen dos tipos fundamentales: extravertido e introvertido, los cuales, a su vez, se expresan de acuerdo con cuatro funciones temperamentales: pensamiento, sentimiento, sensación e intuición. ${ }^{9}$ A continuación, se expondrá una síntesis de tal teoría en la que se destacan los ejes de esta relación.

En un primer término, se destaca la polaridad extraversión/introversión; al respecto afirma el especialista Ruiz Sánchez:

\footnotetext{
Entre las formas de relación de objeto (relaciones con otras personas e intereses) esta la polaridad "extroversión/introversión". Los sujetos extrovertidos están orientados hacia el exterior, hacia las personas, objetos, intereses y situaciones externas. Su reflexión personal esta vinculada a la comprobación y el razonamiento sobre la base de la actividad externa. Los sujetos introvertidos están orientados hacia el interno, especialmente sus pensamientos, reflexiones e imágenes mentales. Los sujetos extremadamente extrovertidos suelen ser caprichosos y volátiles en sus relaciones, los llamados histriónicos en la psicopatología actual. Los sujetos extremadamente introvertidos pueden estar apartados del mundo externo y envueltos en sus ensoñaciones, siendo lo que hoy en día se denominan sujetos esquizoides. La extroversión y la introversión son conceptos de los que se sirve la psiquiatría y la psicología actual para estudiar la personalidad. (Ruiz Sánchez 2001)
}

En segundo lugar, aparece la oposición propia de la sensación y la intuición:

\footnotetext{
Otro eje de relación de objeto es el "eje perceptivo de la sensación y la intuición”. La percepción de la sensación conlleva a apreciar los detalles específicos de las situaciones en el presente. La intuición por su parte es un modo de aprehensión de la realidad psíquica que integra totalidades en vez de partes. Es notable el anticipo de Jung, a lo que posteriormente en psicología se ha dado en llamar estilos cognitivos o estilos de pensamiento. (Ruiz Sánchez 2001)
} 

sentimiento.

Por último, se presenta la tercera oposición correspondiente a pensamiento/ Un tercer eje de relación de objeto está vinculado a como se elabora o procesa la información en la mente
una vez percibida. En esta área Jung habla de la polaridad "pensamiento/sentimiento". Los sujetos con
predominio del pensamiento elaboran sus percepciones sobre la base de juicios basados en la lógica y el
razonamiento, mientras que aquellos en que predominan los sentimientos elabora sus percepciones sobre
la base de sus estados afectivos. ${ }^{10}$

De la combinación, surgen los siguientes tipos psicológicos resultantes. Primeramente, el tipo extravertido de pensamiento es el tipo que se somete al mundo por sus sentidos, pero los piensa y analiza; es un clasificador. El tipo extravertido de sentimiento es conducido por los sentimientos que suele promover en las relaciones con otros. Luego, el tipo extravertido de sensación es materialista y realista, se interesa más por las características físicas. Por último, el tipo extravertido de intuición, en este caso, su impulso lo dirige más por su percepción global que por características definidas.

El segundo gran grupo está integrado por los introvertidos. En este caso, la energía psíquica se orienta hacia el mundo interno del sujeto. El primero es el tipo introvertido de pensamiento, el cual es conducido por ideas prefijadas intelectualmente; con dificultad, entabla relaciones sociales duraderas. Luego, está el tipo introvertido de sentimiento que se deja llevar por los sentimientos que despiertan sus ensueños subjetivos; es una persona soñadora que vive en paz con el mundo. También, está el tipo introvertido de sensación, cuyo impulso básico se conforma por las sensaciones internas; suele ser creativo, artístico. Por último, el tipo introvertido de intuición, el cual se deja llevar por su poderosa imaginación; tiende a ser egocéntrico y autosuficiente; se relaciona con el profeta religioso.

Sin embargo, debe recordarse que estos son tipos construidos heurísticamente, difícilmente se presentan de esta forma pura en la realidad. En todos hay unos niveles moderados y extremos. La gran mayoría de los individuos no coinciden con los tipos puros sino que son ambiversos. Esto permite una mayor integración en la psique de los aspectos dirigidos hacia el interior o hacia el exterior, ya que integran los aspectos de introversión y extroversión, lo cual permite su mejor desarrollo personal. Este proceso permite la organización de la psique.

Dentro de la psicología analítica, la estructura básica de la psique es el inconsciente que, a su vez, está conformado por dos niveles -el inconsciente personal y el colectivo-; frente a ellos está la conciencia. Esta última posee un desempeño de segundo lugar si se compara con los niveles inconscientes, pues su función principal es la de contribuir a que el sujeto se adapte al ambiente y que regule las funciones de manera equilibradora de la máscara (social) y la sombra (lo no aceptado). Es la parte racional y lógica de la personalidad. Dentro de la misma conciencia está el ego, la parte medular de la conciencia. Permite que el sujeto mantenga su sentido de identidad y de continuidad a través de la propia vida, de sí mismo. Esta identidad puede estar amenazada por la psicosis. El ego es el guardián de la conciencia. Si el yo es excesivo o dominante, puede dar origen a las neurosis. Psique y yo, en consecuencia, no se identifican. El ego (yo) organiza la actividad consciente. Sólo conocemos conscientemente el proceso del yo (recuerdos, pensamientos, vivencias concientes).$^{11}$

Por otra parte, el inconsciente personal, según Jung, coincide parcialmente con el inconsciente de Freud. Este contiene los elementos reprimidos y recuerdos olvidados; además, incluye la percepción subliminal, así como los sueños y fantasías personales caídas en el 
olvido o reprimidas. Los procesos inconscientes únicamente pueden ser deducidos a través de actividades como los síntomas, los complejos y los símbolos; sin embargo, y a diferencia de lo que postulaba Freud, este inconsciente personal no se reduce a tener un significado sexual. En efecto, la teoría de la libido de Jung es muy diferente de la de Freud. Para el psicólogo suizo, la libido es la energía psíquica en general que fluye de manera indiferenciada; ciertamente, incluye la pulsión sexual, pero es mucho más que eso, ya que se muestra en todas las diversas facetas de la creatividad y de la fantasía humana. En síntesis, se puede afirmar que la energía vital para Jung es una fuerza que impulsa y engloba todo el quehacer humano, incluyendo la propia sexualidad. Por eso afirma Jung:

\footnotetext{
Todos los fenómenos psicológicos pueden ser considerados como manifestaciones de la energía [...]. Yo la llamo libido, empleando esa palabra en su significado original, que en modo alguno se limita exclusivamente al ámbito sexual. [...] Desde un punto de vista más amplio puede entenderse la libido como energía vital en general o como el élan vital de Bergson. (Jung 2004b: 233)
}

Además de la conciencia y del inconsciente personal, la estructura psíquica se compone de un inconsciente colectivo. Este substrato de la mente es la parte más importante en la vida del sujeto y de las culturas, pues desde ella surgen los sistemas simbólicos. Como afirma Jung: "Lo inconsciente colectivo es la gran masa hereditaria espiritual de la evolución de la humanidad, masa que renace en cada estructura cerebral individual"(Jung 2004a: 160). El concepto de inconsciente colectivo ha sido resumido por Ruiz Sánchez de la siguiente forma:

\footnotetext{
Está presente en todos los individuos desde su nacimiento. Conforma la dimensión objetiva de la psique (frente a la subjetiva del inconsciente personal), al contener la experiencia humana de las generaciones de la humanidad. El inconsciente colectivo está dotado de propósito e intencionalidad, cuya fuerza energética reposa en elementos primordiales o arcaicos, llamados "arquetipos". Esta región de la mente jamás puede enfermar, ya que contiene las experiencias y los mensajes primordiales de la humanidad. Por otro lado el inconsciente colectivo no deriva de las experiencias ambientales y personales del sujeto. (Ruiz Sánchez 2001)
}

Pero, ¿qué hay en este inconsciente colectivo? ¿cuáles son sus componentes esenciales? Jung también ofrece una respuesta a estas interrogantes: el inconsciente colectivo está poblado por arquetipos. En cierto modo, se pueden considerar a los arquetipos como imágenes instintivas y heredadas. R. Robinson, especialista en Jung y en ciencias cognoscitivas, ha propuesto que se los llame invariantes cognitivos. Con ello, quiere señalar dos aspectos, uno negativo y el otro positivo. Por una parte, eliminar la carga filosófica idealista que los acerca a la filosofía propia de las ideas absolutas y eternas del platonismo; pero, por otra, destacar su relación con varios descubrimientos realizados por las ciencias cognoscitivas contemporáneas. En este último caso, los invariantes cognitivos (arquetipos) estarían derivados de procesos epistemológicos de naturaleza empírica observables ya desde la infancia de los individuos.

Los invariantes cognitivos supondrían que la mente del niño no es una tabula rasa, libre y pura como suponía el empirismo ingenuo; sino más bien, una estructura mental configurada desde el nacimiento y desarrollada a través de las experiencias de la vida en compleja interacción con otras personas, con el medio y con la propia madurez neuronal del sujeto. Implica, por supuesto, un largo proceso evolutivo. ${ }^{12}$ Tampoco se deben confundir con la teoría de las ideas innatas. En realidad, Jung está lejos del innatismo psicológico porque, como se ha visto, la noción de arquetipo no implica contenidos mentales específicos, sino más bien constelaciones de tendencias predominantes de naturaleza inconsciente. ${ }^{13}$ 
Los arquetipos en sí mismos no son claramente definibles, ya que son inconscientes; se perciben a través de sus efectos: los mitos, las religiones, los cuentos de hadas, las obras literarias, el cine, el arte, las creencias seculares; así como en otras manifestaciones colectivas, incluyendo las expresiones políticas. Además, constituyen la materia de los sueños, de procesos paranormales y de las manifestaciones de la fantasía individual. El arquetipo siempre oscila entre lo manifiesto y lo oculto; lo definible y lo indefinible. Se presentan como esquemas básicos para la formación del sistema de símbolos; pero no son los mismos símbolos como tales. De acuerdo con Jung los arquetipos

\begin{abstract}
Son sistemas de actitud para la acción y, al mismo tiempo, imágenes y emociones. Se heredan de la estructura cerebral; son su aspecto psíquico. Por un lado representan un conservatismo instintivo muy fuerte, por otro, constituyen el medio más eficaz concebible para la adaptación instintiva. Así que son, esencialmente, la parte ctónica del alma [...], la parte que le ata a la naturaleza o al menos en la que se manifiesta de manera más tangible su vinculación con la tierra y con el mundo. Es seguramente en estas imágenes primigenias donde más claramente nos sale al paso la acción anímica de la tierra y de sus leyes. (Jung 2001: 31)
\end{abstract}

Se tiene entonces una estructura inconsciente que lejos de ser simple es muy compleja. Sus elementos se podrían caracterizar con una imagen del propio Jung: es un alto edificio que se eleva al cielo y en la cumbre se divisa un gran espacio luminoso. En la cumbre, está la conciencia, pero, al ir descendiendo el horizonte se va oscureciendo hasta llegar al mundo prehistórico de los cazadores. Este es el lugar psíquico del origen de los arquetipos presentes en la conciencia y que alimentan la cultura, la literatura, la religión: la madre, el padre, el anciano sabio, el niño como arquetipos antropomorfos; pero, también están los biológicos como el ojo, el corazón y todas las partes del cuerpo masculino y femenino. Además, están los naturales: el fuego, el agua en todas sus formas, el árbol primigenio, el sol, la luna, entre otros. Un importante arquetipo es el de Dios. Jung afirma que el mismo surge a partir del culto al sol. El arquetipo teomorfo constituye un importante centro de organización psíquica. Incluso, la misma imagen de Jesucristo constituye un eje articulador de las funciones yoicas. También hay arquetipos mucho más abstractos como son los propios de las figuras geométricas, en especial el círculo, el cuadrado y el triángulo, así como los correspondientes a los números. Existe entonces una participación originaria que hunde sus raíces en la tierra primigenia. Los arquetipos se producen por medio de un proceso de analogía y semejanza: son el resultado de una especie de aglomeración psíquica de diversos elementos.

Pero, ¿qué impulsa a la formación de los arquetipos y de los símbolos? Para Jung, los arquetipos surgen precisamente por la necesidad de sobrevivir. El ser humano requirió de representaciones, al principio muy simples, luego mucho más complejas, para enfrentarse a un mundo hostil. Los arquetipos funcionaron, y aún funciona, como estructuras que le permiten al individuo una ubicación en el mundo. Además, dan origen a los procesos de adaptación y de comunicación personal e intercultural. La energía psíquica de la libido se utiliza primariamente para las funciones de supervivencia más directas para satisfacer las necesidades (ananké); pero, de la energía sobrante se formaron los símbolos. En realidad, puede decirse que el arquetipo es una estructura con identidad propia, aunque flexible, de la psique humana.

Desde esta misma tierra fértil se manifiesta la dualidad y la polaridad de los dos arquetipos fundamentales: ánima y ánimus. El ánimus es el aspecto masculino interno de la mujer. Constituye una compensación estructural de la psique femenina y actúa de forma inconsciente. Son "las experiencias ancestrales del hombre que tiene la mujer". En la mujer, 
el ánimus es un psicopompo entre lo consciente y lo inconsciente. Es el logos paterno en la psique de la mujer. En los sueños, suele aparecer como padre, amante, sabio o como imagen aterradora y castigadora. Puede ser el ideal masculino, pero también su negación. ${ }^{14}$ El ánima, por el contrario, es el aspecto femenino interno del hombre. Es el arquetipo de la vida misma y la imagen interna de la madre, la hermana, la amada, la diosa celestial y la diosa infernal. En los sueños, aparece como la mujer seductora, el hada, la santa o la mujer perversa. Es su ideal, pero también su negación. Tanto el ánima como el animus cumplen cinco leyes que Ruiz Sánchez ha resumido de la siguiente forma:

\footnotetext{
$1^{\circ}$ - Todo sujeto tiene cualidades masculinas y femeninas inconscientes. La individuación aporta un equilibrio al hombre y mujer que integra adecuadamente los aspectos de su personalidad oculta (la sombra). Un hombre equilibrado es a la vez activo y flexible, racional e intuitivo, posee ternura y dureza, es agresivo y acogedor, etc. Igualmente obraría para una mujer equilibrada.

$2^{\circ}$-Las cualidades masculinas y femeninas cuando se encuentran proporcionadas llevan al equilibrio y la salud mental.

$3^{\circ}$-El anima y el animus son aspectos de la "sombra" del inconsciente.

$4^{\circ}$-Todo lo que no está integrado en la mente, incluido el anima y el animus, corre el riesgo de ser proyectado para bien o para mal. El enamoramiento es un ejemplo de como proyectamos nuestra anima o animus en el ideal o imagen del hombre o mujer ideal de nuestros sueños. Otro ejemplo son las proyecciones de la imagen del padre a través del arquetipo del padre supremo (Dios) que puede ser proyectado en imágenes de castración, autoritarismo, culpabilidad, etc., hacia el propio padre o como se vive una religión concreta. $5^{\circ}$-Si la represión (ontológica) se transforma en consciente cesa la proyección y sus aspectos pasan a ser
integrados. ${ }^{15}$ (Ruiz Sánchez 2001)
}

Como se puede apreciar, tanto el ánima como el ánimus poseen un doble carácter, por un lado, tienen el especto positivo y constructivo de la personalidad; pero, por el otro, pueden ser destructivos y generadores de terrores traumáticos.

Por otra parte, la sombra está conformada por los aspectos inconscientes u ocultos de uno mismo, tanto los positivos como los negativos. Han sido reprimidos por el ego racionalizador, o, en ocasiones, nunca los ha reconocido; es el problema de la represión. Precisamente, el ego actúa como un elemento organizador de los deseos y de las conductas. La sombra se compone de los deseos o impulsos primitivos e instintivos. Constituye la parte no civilizada de la psique donde anidan los resentimientos y las fantasías. Muchas veces se perciben en los demás a través del mecanismo de proyección. La percepción de la sombra es inhibida por la persona. Sin embargo, con un buen insight y un arduo trabajo personal y psicoterapéutico puede ser asimilado hasta cierto punto por la conciencia. Existe, por supuesto, una resistencia propia del control moral que suele estar relacionada con las mismas proyecciones.

Esta oculta faceta de la personalidad, el otro yo, aparece en los sueños, en la literatura, en los mitos. Así, en ocasiones, el enemigo del héroe no es sino el mismo héroe desdoblado, tales son los casos de Gilgamesh y Kumbaba, del Dr. Jekill y Mr. Hide, el retrato de Dorian Gray, Mefistófeles en el Fausto de Goethe. Es frecuente en las parejas literarias, como es el caso de Sherlock Holmes y el Dr. Watson, Don Quijote y Sancho, y muchos otros. Incluso, puede ocurrir algo mucho más grave como es perder la sombra, tal como le sucedió a Peter Schlemiel en el famoso cuento de Hoffmann.

Atravesar con éxito este complejo laberinto consiste en el esfuerzo por integrar esta estructura inconsciente en la psique como un todo de forma armónica; esta es la tarea del 
crecimiento personal, de la individuación, en la cual desempeña un destacado papel el símismo. El sí-mismo debe descender al inframundo; es decir, a las profundidades del Hades. Es el viaje de Hércules a la casa del Hades y Jonás en el vientre de la ballena. Es morir y renacer. Ciclo creciente que no se termina con llegar a un puerto cualquiera. Es la vuelta al origen renacido. Ernesto Cardenal, en el maravilloso poema mito Cántico Cósmico lo condensa:

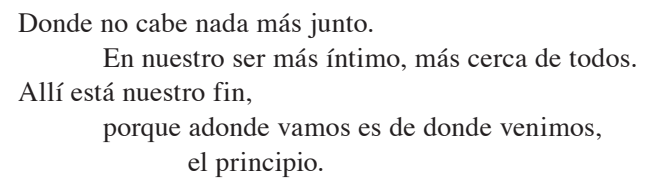

\title{
5. El retorno al hogar: el self y la individuación
}

Es un largo y difícil viaje, no cabe duda. El héroe se ha embarcado para atravesar el abismo del mar. También recorrió el desierto, es decir, el mundo de la infinita soledad. Aún quedan vestigios de sal y de arena en su piel que nunca podrá borrar. ¿Qué le espera ahora? ¿Cuál será su destino? El héroe se aproxima a su hogar. Pero, ¿qué ha ganado con el viaje?¿para qué han servido todas las dificultades y peligros? El héroe, el sí-mismo, el self, como Ulises, regresa y se dispone a tomar el mando de su reino. ¿Quién es este héroe?¿Cuál ha sido su triunfo?

Este héroe no es otro que el sí-mismo, el self. En la obra Tipos psicológicos, ya mencionada, Jung ofrece una definición del sí-mismo o self (selbst):

\begin{abstract}
En cuanto concepto empírico se llama sí-mismo al conjunto íntegro de todos los fenómenos psíquicos que se dan en el ser humano. El sí-mismo expresa la unidad y la totalidad de la personalidad global. Pero en la medida en que esta última, a consecuencia, de su componente inconsciente, nunca puede ser consciente, sino de manera parcial, propiamente el concepto de sí mismo es empírico sólo en parte y, por tanto, en esa misma medida es un postulado. Dicho con otras palabras, el concepto de sí-mismo engloba cosas experimentables y cosas no experimentables o que aún no han sido experimentadas. [...] Dado que en la práctica hay fenómenos de la conciencia y de lo inconsciente, también el sí-mismo, en cuanto totalidad psíquica, tiene un aspecto consciente y otro inconsciente. Empíricamente el sí-mismo aparece en sueños, mitos y cuentos en la figura de "la personalidad de orden superior" como rey, héroe profeta, salvador, etc. O en la figura de un símbolo de totalidad, como círculo, cuadrado, cuadratura circuli, cruz, etc. (Jung 2000: 562-563)
\end{abstract}

Como se puede apreciar en la definición anterior, el sí-mismo constituye el centro, núcleo o eje articulador de la totalidad de las funciones psíquicas. Al igual que cualquier otro arquetipo, se conoce a través de sus manifestaciones, aunque constituye más bien el orden de los demás arquetipos. Es la coincidencia de los opuestos y el corolario de la concurrencia en la psique de la parte inconsciente y la conciencia integradas. En un plano superior, este núcleo psíquico está relacionado con las estructuras religiosas; por eso dice Jung, que se le podría llamar "Dios dentro de nosotros". Obviamente, al decir esto, Jung no pretende hacer ninguna presuposición metafísica ni teológica; es sólo un dato funcional de la psique. En consecuencia, el héroe no es sino el resultado de una de las manifestaciones conscientes del sí-mismo.

Asimismo, se debe tener presente que el ego no es el sí-mismo porque, como se señaló, el sí-mismo es una instancia de articulación de totalidad, consciente e inconsciente, mientras que el yo o ego es un mecanismo de control exclusivo de la conciencia. El sí-mismo es, entonces, la estructura que propicia el equilibrio de la psique. Entre lo consciente y lo inconsciente, entre el ánima o el ánimus según corresponda; y su papel es fundamental para el sano equilibrio emocional del individuo. ${ }^{16}$ 
Por fin el héroe ha logrado constituirse como individuo. Superó las falsas máscaras de la persona, que si bien le sirvieron en varias ocasiones durante el viaje para enfrentar los peligros, en este momento sólo son restos inoportunos. Ahora, la sombra es parte de su historia personal consciente. Ha logrado desarrollar su personalidad individual. Por fin está en posición de responder a la acuciante pregunta que todo ser humano se formula, explícita o tácitamente: ¿Quién soy yo? Se encuentra despojado de los falsos atuendos de la persona; ha podido integrar las partes primitivas de su personalidad y ha conseguido moldear el carácter en una totalidad integral destronando las ilusorias defensas que se presentaban como complejos o como imágenes ilusorias.

Escuchó la llamada interior y rompió con la sociedad normal, que se caracteriza por ser impositiva,consumista y represiva, verdadero naufragio que encierra al sí-mimo con las compulsiones del falso yo, cuya expresión mas conocida es debes, es necesario, haz esto y aquello, no puedes. Rompió las máscaras impuestas y descubrió, en el fondo de su ser, como una perla escondida, la semilla del auténtico self. Viajó solo.

\footnotetext{
Cuando alguien entra en la parte más profunda del alma humana, no puede pedirle a otro que lo acompañe. Paso a paso, debe descender el camino hasta el fondo. Cuando al final encuentra algo que brilla, lo guarda en su pecho, y desanda el camino realizado para compartirlo con los demás. (Nomura citado en Nouwen \& Nomura 2002: 106)
}

Fue difícil. Pero aprendió a conocerse y a vivir con las facetas que no le gustan o que no conocía de su propia personalidad. Aunque sabe que nunca podrá eliminarlas del todo, ahora las reconoce como propias. También comprendió cuáles son sus auténticas fortalezas y sus verdaderas limitaciones. Se percata de que no es perfecto, ¿quién lo es? Ha logrado integrar lo subjetivo con su comprensión objetiva, su ánima o su ánimus, los fantasmas de su sombra ya no lo atemorizan. Y, lo que es muy importante, alcanzó un equilibrio creativo entre el sí- mismo y la colectividad. Es un individuo en buenas relaciones de intercambio con el entorno social: no desprecia las normas, pero no se apega a ellas. A diferencia del individualismo, el proceso de individuación no desatiende las normas sociales como tales, sino que propicia un proceso de interacción creativa con el entorno social. Si alguien quiere eludir el sufrimiento propio de la condición humana, entonces se busca sufrimientos sustitutos: las neurosis y las psicosis.

En este proceso, los sueños desempeñan un papel singular. Si el sujeto aprende a revivir los símbolos oníricos, esta hermenéutica le ayudará a conocer los complejos y a desarrollar las estrategias y las vías de solución de los mismos. Contribuye a eliminar o, por menos, diluir, los trastornos psíquicos. También es útil el método de la imaginación activa. Consiste en un estímulo de las capacidades creadoras de símbolos propias de la psique para crear productos espontáneos en los que los contenidos inconscientes se concretan en forma de palabras, sonidos musicales, pintura, dibujo, escultura, danza, entre otros. ${ }^{17} \mathrm{Ha}$ descubierto la riqueza interior de su alma.

Por lo demás, es muy importante anotar que el proceso de individuación no consiste en la toma de conciencia del yo (ego). Si así fuera, el sujeto se convertiría en un egocéntrico insensible y antisocial. Es decir, se construiría una máscara más fuerte y no podría salir del laberinto. La ballena se lo tragaría para siempre. Jonás no podría predicar la palabra de Dios ni Pinocho se convertiría en el niño de carne y hueso. Después de cien años de soledad, ¿tendrán las generaciones otra oportunidad sobre la tierra? Como se ha dicho, a diferencia del yo, el sí-mismo incluye una serie de elementos y de factores que buscan su equilibrio. En realidad, la individuación nunca termina. El héroe podrá llegar a casa, pero sus tareas, 
quizás ahora mucho más pequeñas, van a continuar. Deberá luchar contra los pretendientes y redimir el amor de la fiel Penélope. Sus trabajos y sus días se extenderán hasta que ya no tenga más días.

Sin embargo, este regreso, supuso un crecimiento personal. Descubrió que podía integrar los opuestos; equilibrar la conciencia y la inconciencia; lo personal y lo colectivo, el ánima o el ánimus; en fin, el yin y el yang o la pareja real de la alquimia. Descubrió valores novedosos al romper las falsas apariencias de los complejos y de las máscaras al superar los temores de la sombra y las seducciones mortales y destructivas (thanatos) impuestas por el éxito externo y los bienes materiales; ahora es más creativo, y con más valores artísticos, morales y religiosos. Es el pleno eros libidinal y espiritual de un alma renovada. Descendió al Hades, pero surgió victorioso del inframundo. Murió y renació. El equilibrio le ha otorgado más armonía y riqueza personal. Ha comprendido que el proceso de maduración consiste en aceptar la cruz con la cual se debe caminar, pero que nada sobrepasa al valor del conocimiento personal y así puede responder por fin a la acuciante pregunta sobre la identidad. El socrático conócete a ti mismo tiene por fin su respuesta: este soy yo: " "La meta sólo es importante como idea, pero lo esencial es el opus que conduce a la meta, pues llena con un sentido la duración de la vida" (Jung 2006: 191).

\section{Evocación de la odisea}

Este trabajo no ha concluido. Pero, ¿en realidad puede concluir un examen sobre el mito? Como se ha visto, el mito no es solamente una parte constitutiva de la historia social y personal del ser humano. Es también su condición de posibilidad de crecimiento y de maduración.

Numerosos investigadores -historiadores, sociólogos, filólogos, filósofos, críticos literarios, lingüistas, politólogos, teólogos, etc.- se han dado a la compleja tarea de investigar diversas facetas del mito y del símbolo. Aporte esencial ha sido el de la antropología con nombres como Levy-Strauss, M. Mead, entre otros. También psicólogos del pasado y del presente, desde diversas ópticas, se interesan por este tema; entre ellos hay que recordar las contribuciones de Freud, Janet o W. James. Recientemente, el interés ha cobrado nuevo auge, en parte inspirado por el extraordinario desarrollo de la investigación sobre el mito que han llevado a cabo las ciencias de la religión; pero también por el propio desarrollo de la investigación teórica y metateórica sobre el proceso psicoterapéutico. La psicoterapia, es decir, la intervención clínica, de nuevo ha valorado la importancia de las creencias -mitos, símbolos, pensamientos irracionales, etc.- como parte de un adecuado tratamiento. Asimismo, las investigaciones desarrolladas por las neurociencias, en particular por la neuropsicología, han ofrecido un interesante campo de reflexión y de aplicación clínica. Por ello, no es de extrañar que importantes psicoterapeutas en la actualidad se refieran al tema de las creencias y del mito como parte de la exploración psicológica. ${ }^{19}$

Las aportaciones que hizo Jung son numerosas y, como se ha indicado, sobrepasan el ámbito de la psicología en sentido estricto, pues su impacto alcanza el arte, la literatura, la ciencia, la mitología, la filosofía, la teología, entre otras. Ya se han señalado varios conceptos claves, tales como el de complejo, inconsciente, inconsciente colectivo, paralelismo de la psique individual con la colectiva, tipos psicológicos, entre otros. A continuación, se hará un breve bosquejo de varias de estas aportaciones esenciales. ${ }^{20}$ 
a. Jung realiza una nueva formulación del concepto de libido; se refiere no sólo a la sexualidad, sino al conjunto de la energía vital que fluye por la psique en movimiento incesante; a veces elevándose, a veces disminuyendo, haciendo posible un acceso funcional a los hechos psíquicos.

b. Entiende la psique como sistema autorregulador en el cual los reinos conscientes e inconscientes se relacionan compensatoriamente.

c. Además, junto al inconsciente personal existe en la psique humana el inconsciente colectivo o universal, que contiene el conjunto de la herencia espiritual de la evolución de la humanidad. Con esta concepción ,Jung introduce en psicología el concepto de alma entendida psíquicamente.

d. También el concepto de arquetipos o invariantes cognitivos, que se encuentran en el campo heurístico de inconsciente, que distingue entre los contenidos del inconsciente personal y los del inconsciente colectivo. Es decir, aquellos patrones de comportamiento o acciones y reacciones de la psique que son universales, aunque están determinados por la cultura, y que Jung llamó arquetipos. Constituyen potencialidades imperceptibles que se manifiestan como patrones y procesos (símbolos) arquetípicos perceptibles sólo bajo ciertas condiciones psíquicas. Se manifiestan a través de los sueños, visiones y fantasías de los seres humanos y se han expresado en mitos, conceptos religiosos, cuentos de hadas, epopeyas y obras de arte de todas las épocas y todas las culturas. Por lo demás, no se debe olvidar que existe una relación entre el arquetipo y el instinto.

e. El proceso de individuación, es decir, "de la evolución de la psique hacia su totalización”, es su forma de madurar psicológicamente. Durante este proceso, aparecen los arquetipos como elementos estructurales y reguladores del material psíquico inconsciente, los cuales constituyen factores particularmente dinámicos. Las fases de ese proceso se caracterizan por la confrontación de lo consciente con diversos componentes propios del reino inconsciente. Entre ellos, Jung, supone una polaridad de anima/animus o componente femenino y masculino; también, de la sombra, como imagen oscura presente en toda psique; el héroe, la víctima, la gran madre, la madrastra, el viejo sabio, y otros. Es evidente la importancia de estos temas para la comprensión literaria. En especial, parece un esquema clarificador de las funciones estereotípicas de la poeticidad ficcional recurrente en el discurso literario.

f. La función religiosa recibe una consideración especial. Es un elemento integrante de la salud mental en la integración de la psique, su expresión inadecuada o su rechazo suelen originar trastornos psíquicos. Pero recuérdese que por religión no se hace referencia a una determinada estructura confesional sino, más bien, a la disposición ontológica del ser humano. Disposición de base que aparece recurrentemente en las obras literarias.

g. Jung elabora una clasificación de los tipos psicológicos. Se fundamenta en la diferencia entre dos tipos de actitudes: el extravertido (orientado hacia el mundo exterior); y el introvertido (orientado hacia el mundo interior); así como de ciertos tipos funcionales caracterizados por la primacía del pensamiento, la intuición, el sentimiento y la sensación, respectivamente. La caracterología tipológica no implica de modo alguno una taxonomía estática. Es únicamente una aproximación funcional a los tipos 
psicológicos, fenómeno recurrente en la literatura, y en forma particular en el narrativa referente al arquetipo del héroe.

h. La interpretación de los sueños, utilizando los elementos de los sueños del sujeto como representaciones de datos intrapsíquicos, consigue un conocimiento profundo de las proyecciones del sujeto y facilita la disminución de los síntomas. En contraste con la interpretación causal-reductora de Freud, se desarrolla con el método de la ampliación orientado hacia el futuro del proceso inconsciente.

i. El concepto de regresión adquiere un significado positivo. El de neurosis y el de complejo también recibe una nueva definición, liberándolo de las ataduras de lo biológico y de los instintos y dándole, como a la regresión, un sentido espiritual mucho más profundo ligado al concepto de alma. En este caso, la aproximación desde la psicología analítica no parece que conduzca hacia un cierre hermenéutico sino más bien constituye una apertura a posibles lecturas de la ficcionalidad poética.

j. Es importante notar que la aproximación al discurso literario desde la psicología analítica puede ser un elemento enriquecedor desde una epistemología renovadora. En este, como en cualquier otro caso, ese debe evitar todo reduccionismo y fundamentalismo metodológico y epistemológico que podrían negar la aproximación constitutiva del objeto literario ocasionando una clausura de la pluralidad significativa. El riesgo ha sido el de convertir los textos literarios en protocolos clínicos (García Berrío 1994) desplazando o anulando la poética del discurso ficcional en sentido estricto.

k. Parece confirmarse lo señalado al inicio de este trabajo, a saber, que el método psicológico aplicado a la literatura no es un esfuerzo vano, sino todo lo contrario, es un factor enriquecedor e iluminador. Desde la óptica de la psicología analítica, los arquetipos constituyen la articulación subyacente de la expresividad literaria.

1. Porque es sabido que la obra literaria es abierta y susceptible de diversas aproximaciones interpretativas. En este caso, la teoría de los arquetipos propuesta por Jung supone la idea de macroestructuras que operan en la construcción del sentido poético otorgándole a la ficcionalidad literaria, no sólo el valor de la representación de lo existente sino la función de articular un enlace entre la representación y la realidad. Fantasía, concepto, realidad y representación se articulan en la operatividad de los arquetipos.

Para Jung, la vida del ser humano es esencialmente un viaje de crecimiento simbólico y mítico. Es un viaje a través de complejas polaridades psíquicas: anima-animus, extravertidointrovertido, consciente-inconsciente, nivel objetivo-nivel subjetivo, social-individual, llamado a la aventura-regreso a la quietud del hogar... En efecto, después de un largo periplo a través del desierto y del mar; luego de vencer obstáculos casi insuperables, el héroe retorna a la calidez acogedora del hogar. El laberinto es ahora sólo un recuerdo; las tinieblas se han disipado: impera la luz. Pero, ¿por cuánto tiempo? El viaje del héroe es un círculo. Ha luchado contra los monstruos; los derrotó y de esta forma consiguió su liberación. Al final, debe regresar a sus orígenes y debe dar testimonio ante los demás. El viaje del héroe es algo simple: seguir la vocación (vocatus); el camino original donde se labra el carácter en la riqueza misteriosa de la tradición. Jung lo resume con estas enigmáticas palabras: "No dices nada ni revelas nada, ¡oh, Ulises!, pero actúas. Penélope no necesita tejer ya su eterna urdimbre, ahora se pasea por los jardines del mundo, pues su esposo ha regresado de sus descarríos. Un mundo sucumbió y se rehizo" (Jung 2002: 121). 


\section{Notas}

1. Se parte del principio que afirma la función mítico-religiosa en la constitución antropológica del ser humano. Tema que ha sido estudiado por autores como Joseph Campbell. 1977. The masks of God. New York: Penguin. Mircea Eliade. 1972. Tratado de historia de las religiones. México: ERA. Ernst Cassirer. 1978. Filosofía de las formas simbólicas. México: Fondo de Cultura Económica. Más recientemente en la obra de Marià Corbí. 2007. Hacia una espiritualidad laica.Barcelona:Herder; también por James Hillman en sus numerosas obras; entre otros. En este trabajo se presupone este principio filosóficoantropológico.

2. Es importante una precisión. El concepto de mito no implica una fabulación imaginaria sin referente psíquico tal como puede ser el cuento, la fábula o la leyenda. En estos tipos de relatos la presencia del mito puede ser implícita o explícita. Como se verá, el mito tiene sus propias características y leyes narrativas y psico-funcionales. Cf. G.S. Kirk. 1999. El mito. Su significado y funciones en la antigüedad y otras culturas. Barcelona: Paidós Ibérica, S. A.

3. Es, pues, el ser humano un ser creador de mitos, de concepciones simbólicas y religiosas, es, en este sentido, un homo religiosus. Julien Ries. 1995. (ed.). Tratado de antropología de lo sagrado. Vol. I. Madrid: Trotta.

4. Se utilizará el término analítico para referirse exclusivamente a la psicología desarrollada por Carl Jung y su escuela, también llamada psicología compleja o junguiana. Por lo tanto, no debe confundirse con la psicología psicoanalítica de corte freudiano, ni con el macro análisis psicológico de naturaleza cognitiva.

5. Lara Peinado, Federico. (edit.) 1984. Mitos sumerios y acadios. Madrid: Editoria Nacional. También, Alvarado, Manuel. Apuntes del curso Mitología y literatura: la aventura del héroe. Maestría en literatura. Universidad de Costa Rica. 2007.

6. Algunas de sus obras más importantes son las siguientes: Símbolos de transformación, Tipos psicológicos, Psicología y religión, Psicología y alquimia, Aion, Sobre la energética del alma, Psicología y simbólica del arquetipo, La interpretación de la naturaleza de la psique, La práctica de la psicoterapia, Mysterium Coniunctionis, El hombre y sus símbolos (en colaboración con varios discípulos), así como su interesante autobiografía Recuerdos, sueños y pensamientos. Véase la Bibliografía al final de este mismo trabajo.

7. Una importante presentación biográfica es la escrita por Deirdre Bair. 2003. Jung. A Biography. New York-Boston: Back Bay Books. Otra interesante es la de Gerhard Wehr. Jung. (Barcelona: Paidós; 1991). Importante también es el artículo, ya clásico, de su discípula, Jolande Jacobi. 1973. C. G. Jung, publicado en la Enciclopedia Internacional de las Ciencias Sociales. Vol. 6. Madrid, Aguilar.

8. Bair. Op. cit. Cap. 35. Como resultado de estas investigaciones son sus escritos sobre la sincronicidad. Estos trabajos fueron publicados con el sugestivo título de La interpretación de la naturaleza y la psique (Barcelona, Paidós, 1983). En la edición de las obras completas están en el volumen 8 titulado La dinámica del inconsciente. (Madrid: Trotta; 2004).

9. Carl Gustav Jung. 2000. Tipos psicológicos. Buenos Aires: Sudamericana. También, Daryl Sharp. 2002. Tipos psicológicos junguianos. Santiago de Chile: Cuatro Vientos.

10. Id. Véase también: C. G. Jung. 1970. Los complejos y el inconsciente. Madrid: Alianza Editorial. 
11. C. G. Jung. 2004. Consideraciones teóricas acerca de la esencia de lo psíquico. (En) Obras Completas Vol. 8. Madrid: Trotta.

12. R. Robinson. 2002. Introducción a la psicología junguiana. Barcelona: Obelisco;. Cap. 2. La psique. Pp. 45-48. Una presentación general de este tema en H. Gardner. 1987. La nueva ciencia de la mente. Barcelona: Paidós Ibérica. También, J. M. Rodríguez Zamora. "Lo que las ciencias cognoscitivas le dicen a la filosofía”. Revista de Filosofía. Universidad de Costa Rica.

13 Sin embargo, y aunque el nombre es desafortunado, hecha esta salvedad se podría seguir utilizando este concepto dentro de los límites científicos señalados y como un recordatorio de la teoría psicológica a que dio lugar.

C.G. Jung. 1974. Dreams. New jersey: Princeton University Press.

Ruiz Sánchez. Op. Cit. También la obra colectiva, C.G. Jung et al. 1969. El hombre y sus símbolos. Madrid: Aguilar.

Marie-Louise von Franz. 1993. Psychotherapy. Boston \& Londres: Shambala. Cap.VII: Some Aspects of the Transference.

Von Franz. Op. cit. Cap.IV. On Active Imagination.

El tema de la integración psíquica que presupone la superación de las polaridades para lograr la coincidencia de los opuestos es analizado por Jung con detalle en su extensa obra de madures, 2002. Mysterium Coniunctionis. Obras completas. Vol 14. Madrid: Trotta.

Tales son los casos de Drewermann, Tournier y, en especial, el discípulo de Jung, James Hillman. En ellos, a pesar de sus diferencias teóricas y de estrategias clínicas, se encuentra un marcado interés por las creencias racionales o irracionales, por los pensamientos conscientes o disruptivos, y por los valores que enmarcan la vida del sujeto como factores relevantes dentro del proceso psicoterapéutico.

No es tarea fácil hacer un breve bosquejo de la obra junguiana. El problema se agrava por el hecho de que el propio Jung nunca hizo ninguna síntesis. Se tomaran varias ideas de Jacobi y de Robinson. Cf. Jacobi 1973.

\section{Obras de C. G. Jung}

La edición crítica de las obras completas de Jung en español está en curso de publicación por la editorial Trotta de Madrid bajo la supervisión de la Fundación C. G. Jung de España y la Erbengemeinschaft C. G. Jung de Zurich. Hasta el momento se han publicado 12 de los 20 tomos proyectados; además se tiene planeado incluir cuatro complementos. En general, esta edición sigue el orden de la edición en inglés de las obras completas cuyo plan original fue revisado por el propio Jung; así como de la última versión alemana. Los volúmenes ya publicados son los siguientes:

1. Estudios psiquiátricos

4. Freud y el psicoanálisis

7. Dos escritos de psicología analítica

8. La dinámica del inconsciente 
9-1. Los arquetipos y el inconsciente colectivo

10. Civilizaciones en transición

12. Psicología y alquimia

14. Mysterium Coniunctionis

15. Sobre el fenómeno del espíritu en el arte y en la ciencia

16. La práctica de la psicoterapia

17. Acerca de la psicología de la religión occidental y de la religión oriental

18-1. La vida simbólica

\section{Bibliografía}

Bair, Deirdre. 2003. Jung. A Biography. New York-Boston: Back Bay Books.

Campbell, Joseph. 1977. The masks of God. New York: Penguin.

1999. El héroe de las mil caras. Psicoanálisis del mito. México: Fondo de Cultura Económica.

Cardenal, Ernesto. 1999. Cántico Cósmico. Cantiga 43: Omega. Madrid: Trotta.

Cassirer, Ernst. 1978. Filosofía de las formas simbólicas. México: Fondo de Cultura Económica.

Chevallier, J. \& A.Gheerbrant. 1999. Diccionario de símbolos. Barcelona: Herder.

Corbí, Marià. 2007. Hacia una espiritualidad laica. Sin creencias, sin religiones, sin dioses. Barcelona: Herder.

Derrida, J. 1989. La escritura y la diferencia. Barcelona: Anthropos.

Dostoyevsky, F.M. 1966. El idiota. Obras Completas: Tomo I. Madrid: Aguilar

Eco, U. 1989. La estructura ausente. Barcelona: Lumen.

Eliade, Mircea. 1972. Tratado de historia de las religiones. México: ERA.

1978. Historia de las creencias y de las ideas religiosas. Madrid: Cristiandad.

Frazer, James G. 2000. The Golden Bough. A History of Myth and Religion. Londres: Chancellor Press.

García Berrio, A. 1994. Teoría de la literatura (la construcción del significado poético). Madrid: Cátedra. 
García Márquez, Gabriel. 2008. Cien años de soledad. Bogotá. Norma.

Gardner, H. 1987. La nueva ciencia de la mente. Barcelona: Paidós Ibérica.

Hillman, James. 1991. A Blue Fire. Nueva York: Harper Perennial 1998. El código del alma. La respuesta a la voz interior. Barcelona: Martínez Roca.

2004. El sueño y el inframundo. Barcelona: Paidós ibérica, S. A.

Homero. 1966. Odisea. (Traducción de Luis Segala y Estalella). Madrid: Aguilar.

Jacobi, Jolande. 1973. “C. G. Jung”. Enciclopedia Internacional de las Ciencias Sociales. Vol. 6. Madrid: Aguilar.

Jung, C. G. et al. 1969. El hombre y sus símbolos. Madrid: Aguilar.

Jung, C.G. 1974. Dreams. New Jersey: Princeton University Press.

1982. Símbolos de transformación. Barcelona: Paidós Ibérica.

1984. Símbolos de transformación. Cap. V: La génesis del hombre. Barcelona: Paidós. 1995. Tipos psicológicos. Buenos Aires: Sudamericana.

2000a. Psyche \& Symbol. A Selection from the Writings of C. G. Jung. New York: Doubleday anchor Books.

2000b. Recuerdos, sueños, pensamientos. Barcelona: Seix Barral.

2001. Alma y tierra. Obras completas. Vol. 10. Madrid: Trotta.

2002. Ulises. Un monólogo. Obras completas. Vol. 15. Madrid: Trotta.

2004a. La estructura del alma. Obras completas. Vol. 8. Madrid: Trotta.

2004b. Sobre psicoanálisis. Obras completas. Vol. 8. Madrid: Trotta.

2005. Archetypen. Munich: Deutscher Taschenbuch Verlag.

2005. Sobre el amor. Madrid: Trotta. 
2006. La psicología de la transferencia. Obras completas. Vol. 16. Madrid: Trotta.

Kirk, G.S. 1999. El mito. Su significado y funciones en la antigüedad y otras culturas. Barcelona: Paidós Ibérica, S. A.

Lara Peinado, Federico (ed.). 1984. Mitos sumerios y acadios. Madrid: Editora Nacional.

Mann, Thomas. 2005. La montaña mágica. Barcelona: EDHASA.

Martínez Bonati, F. 1972. La estructura de la obra literaria. Barcelona: Seix Barral.

Merton, Thomas. 2008. La montaña de los siete círculos. Barcelona: EDHASA

Neumann, Erich. 1993. The Origins and History of Consciousness. New Jersey: Princeton University Press.

Nouwen, Henri \& Yushi Nomura. 2002. La sabiduría del desierto. Buenos Aires: Claretiana.

Quiroga, M. Pilar. 2003. C. G. Jung. Vida, obra y psicoterapia. Bilbao: Descleée de Brouwer.

Ricoeur, P. 1980. La metáfora viva. Madrid: Europa.

Ries, Julien (ed.). 1995. Tratado de antropología de lo sagrado. Madrid: Trotta.

Robinson, R. 2002. Introducción a la psicología junguiana. Barcelona: Obelisco.

Robles Robles, J. Amando. 2001. Repensar la religión. De la creencia al conocimiento. Heredia: EUNA.

Rodríguez Zamora, José Miguel. 2001. "Lo que las ciencias cognoscitivas le dicen a la filosofía”. Revista de Filosofía. 39(99): 13-28.

2002. "El ser en la palabra: sobre el texto poético como filosofía". Revista de Filología y Lingüística. 28(1): 57-67.

2004a. "Análisis estructural y significado lingüístico". Revista de Filología y Lingüística. 30(1): 181-203.

2004b. "Estructura semántica y análisis ideológico". Revista de Filología y Lingüística. 30(2): 155-169.

Ruiz Sánchez, Juan José. 2001. Teoría de la mente y los sueños . http://www.psicologia-online.com. Consulta: mayo 2007. 
Sharp, D. 1998. Lexicon jungiano. Santiago de Chile:Editorial Cuatro Vientos. 2002. Tipos psicológicos junguianos. Santiago de Chile: Cuatro Vientos.

Von Franz, Marie-Louise. 1993. Psychotherapy. Boston \& Londres: Shambala. Wehr, Gerhard. 1991. Jung. Barcelona: Paidós.

Widengren, Geo. 1976. Fenomenología de la religión. Madrid: Cristiandad.

Zweig, C. \& J. Abrams (eds.) 2002. Encuentro con la sombra. Barcelona: Kairós. 